AUTOR:

NIIBA LIMA DE SOUZA

ORIENTADOR:

Profa. Dra. Ana Cristina Pinheiro

Fernandes AraúJo

\title{
Experiência materna com recém-nascido prematuro advindo de gravidez de risco
}

\author{
Maternal experiences undergone after a premature delivery resulting from \\ a bigh risk pregnancy
}

Resumo de tese

Palavras-chave

Gravidez

Pré-eclâmpsia

Prematuridade

Grupo focal

Humanização da assistência

Keywords

Pregnancy

Pre-eclampsia

Prematurity

Focal group

Humanization of assistance

AUTOR:

ThOMAS GABRIEL MiKLOS

ORIENTADOR:

Prof. Dr. Nilson Donadio

Resumo de tese

Palavras-chave

Fertilização in vitro Infertilidade feminina

Ovário/fisiologia

Indução da ovulação

Testes de função ovariana

Keywords

In vitro fertilization

Female infertility

Ovary/Fisiology Induction ovulation

Ovary function test
Dissertação de Mestrado, apresentada ao Programa de Pós-graduação em Ciências da Saúde do Centro de Ciências da Saúde da Universidade Federal do Rio Grande do Norte - Brasil, em 8 de dezembro de 2005.

OBJETIVO: conhecer as experiências maternas diante de um nascimento prematuro advindo de gravidez de risco, durante o internamento do filho na Unidade de Terapia Intensiva Neonatal (UTIN) e, após-alta, no ambiente domiciliar. MÉTODOS: utilizou-se a técnica do grupo focal por meio de um roteiro semi-estruturado para obtenção dos relatos maternos. Foram selecionadas 28 mulheres, com média de nove participantes por grupo. As reuniões foram realizadas durante o internamento do recém-nascido e 30 dias após a alta. Avaliaram-se o conhecimento da gestante sobre a gravidez de risco e a correlação desta com a prematuridade; as experiências oriundas da internação do bebê prematuro e no convívio familiar; além do tipo de comunicação entre equipe de Saúde e pacientes. RESULTADOS: os conteúdos foram analisados em cinco categorias: conhecimento da gravidez de risco; vivências com o internamento do recém-nascido pré-termo; relacionamento/comunicação equipe-pacientes; vivências com o recém-nascido no domicílio e seguimento ambulatorial da pré-eclâmpsia. CONCLUSÃO: existe um grau relevante de desinformação das mulheres sobre a gravidade das síndromes hipertensivas da gravidez e a maioria das mulheres não estava fazendo o seguimento ambulatorial da pré-eclâmpsia; sentimentos de medo, choque, tristeza e inseguranças foram vivenciados com o neonato pré-termo durante e após o internamento; existem lacunas no processo de comunicação profissional-paciente no serviço avaliado.

\section{Concentração sérica do hormônio anti-mülleriano como marcador da resposta à hiperestimulação ovariana com gonadotrofina exógena em mulheres com indicação de fertilização in vitro - estudo preliminar}

\author{
Serum concentration of anti-müllerian hormone as a marker of the answer to \\ the ovarian byperstimulation with exogenous gonadotrophin in women with \\ indication of in vitro fertilization - preliminary study
}

Dissertação apresentada ao curso de Pós-graduação do Departamento de Obstetrícia e Ginecologia da Faculdade de Ciências Médicas da Santa Casa de São Paulo, para obtenção do título de Mestre em Medicina, em 24 de outubro de 2007.

hormônio anti-mülleriano (AMH) tem sido proposto recentemente como marcador da resposta ovariana frente ao hiperestímulo ovariano controlado em pacientes visando à fertilização in vitro (FIV), uma vez que o AMH é produzido pela células da granulosa dos folículos pré-antrais e antrais pequenos. OBJETIVO: avaliar o AMH como teste da resposta folicular em pacientes que serão submetidas à indução da ovulação para FIV. MÉTODOS: foram selecionadas 24 pacientes com indicação de FIV. Foram analisadas concentrações séricas de $\mathrm{AMH}$, inibina B, FSH, E2, LH e FSH/LH de amostras de sangue periférico colhidas no terceiro dia do ciclo. Utilizamos o método de ELISA para as dosagens séricas do AMH. Estas pacientes foram submetidas ao protocolo longo de indução da ovulação sendo posteriormente classificadas em más respondedoras (MR) e em boas respondedoras (BR), em baseadas no número de folículos encontrados no dia da punção ovariana para captação de ovócitos. RESULTADOS: encontrou-se uma correlação significante entre o AMH e a condição da paciente ser MR ou BR. Observaram-se também diferenças significantes nas variáveis idade, dias de estímulo, número de folículos, FSH, inibina B e AMH entre os grupos MR e BR. Pela análise da curva de ROC, para a variável $\mathrm{AMH}$, o ponto de corte sugerido foi $1,85 \mathrm{ng} / \mathrm{mL}$ para estimar MR ou BR. CONCLUSÕES: o AMH parece ser um marcador da resposta folicular em pacientes submetidas à FIV. 